\title{
Protein Expression of STAT3, pSTAT3, MMP-7 and VEGF in Colorectal Adenocarcinoma: An Immunohistochemical Study
}

\author{
Rakesh Naidu1 ${ }^{*}$, Lim Vin Nee², Mak Joon Wah ${ }^{2}$, Kevin Moissinac ${ }^{3}$, A. Rahman A. Jamal4, \\ Isa Mohd Rose5, Yunus Gul Alif Gul'6, Patricia Lim Kim Chooi' ${ }^{2}$, Gregory Tan Jin San ${ }^{7}$ \\ ${ }^{1}$ School of Medicine and Health Sciences, Monash University Malaysia, Selangor, Malaysia \\ ${ }^{2}$ International Medical University, Kuala Lumpur, Malaysia \\ ${ }^{3}$ Department of Surgery, Penang Medical College, Pulau Pinang, Malaysia \\ ${ }^{4}$ Department of Paediatrics, Faculty of Medicine, Universiti Kebangsaan Malaysia, Kuala Lumpur, Malaysia \\ ${ }^{5}$ Department of Pathology, Faculty of Medicine, Universiti Kebangsaan Malaysia, Kuala Lumpur, Malaysia \\ ${ }^{6}$ Department of Surgery, Faculty of Medicine and Health Sciences, Universiti Putra Malaysia, Selangor, Malaysia \\ ${ }^{7}$ School of Health Sciences, The University of Notre Dame Australia, Fremantle, Australia \\ Email: ${ }^{*}$ kdrakeshna@hotmail.com
}

Received 14 August 2014; revised 10 September 2014; accepted 6 October 2014

Copyright (C) 2014 by authors and Scientific Research Publishing Inc.

This work is licensed under the Creative Commons Attribution International License (CC BY).

http://creativecommons.org/licenses/by/4.0/

c) (i) Open Access

\section{Abstract}

Background: The purpose of the present study is to investigate the expression levels of STAT3, pSTAT3, MMP-7 and VEGF in colorectal adenocarcinoma, and also to determine association with the clinico-pathological parameters and co-expression of these genes. Methods: An immunohistochemical method was used to evaluate the expression of MMP-7 and VEGF genes in 93 archival tissues whereas STAT3 and pSTAT3 expression was determined in 75 cases. Results: Overexpression of STAT3 was detected in $26.7 \%(20 / 75)$, pSTAT3 in $13.4 \%(10 / 75)$, MMP-7 in $38.8 \%(36 / 93)$ and VEGF in 59.2\% (55/93) of the colorectal carcinomas. STAT3, MMP-7 and VEGF immunopositivity were significantly correlated with poorly-differentiated tumors $(P=0.004 ; P=0.03 ; P=$ 0.002 , respectively) but not with other parameters. However, pSTAT3 immunostaining was not significantly associated with the clinico-pathological characteristics. Significant relationship was noted between overexpression of pSTAT3 and STAT3 $(P<0.001)$, pSTAT3 and VEGF $(P=0.044)$, pSTAT3 and MMP-7 $(P=0.003)$, and STAT3 and VEGF $(P=0.037)$ but marginal association was detected between STAT3 and MMP-7 $(P=0.057)$, and MMP-7 and VEGF $(P=0.052)$. Conclusion: Our data suggest that expression of these genes may have an important role in tumor dedifferentiation and may be useful as indicators of biologic aggressiveness. Co-expression of the bio-

\footnotetext{
${ }^{*}$ Corresponding author.
} 
markers by cancer cells may have important implications in colorectal cancer biology and could be useful biological markers of the malignant phenotype.

\title{
Keywords
}

\author{
STAT3, pSTAT3, MMP-7, VEGF, Colorectal Adenocarcinoma
}

\section{Introduction}

Signal transducer and activator of transcription 3 (STAT3) is involved in the JAK-STAT signaling pathway that mediates a wide variety of cellular responses depending on the tissue type such as differentiation, proliferation, apoptosis and survival [1]. STAT3 is constitutively activated in various human epithelial malignancies, including prostate, breast, lung, head and neck, brain, pancreas and colorectal cancer [2]-[4] as well as haematopoietic malignancies [2] suggesting its importance in oncogenesis. Cellular transformation by activated STAT3 occurs through the transcriptional regulation of specific target genes including those encoding the anti-apoptotic proteins Bcl-xl, Mcl-1, and Bcl-2, the proliferation-associated proteins Cyclin D1 (CCND1) and Myc, and the proangiogenic factor VEGF [2] [5] [6]. Activation of STAT3 also contributes to invasive growth of cancer cells and confers resistance to chemotherapy [3] [7]. Elevated levels of STAT3 were significantly associated with poor prognosis [8] [9] and metastasis [3] in colorectal carcinomas (CRCs).

The matrix metalloproteinases (MMPs) family consists of proteolytic enzymes that are involved in the degradation of extracellular matrix components [10]. MMPs are often overexpressed during tumor progression and have been associated with tumor invasion and metastasis [11]. MMP-7, a member of the MMP gene family, has proteolytic activity against a wide range of substrates such as collagens, proteoglycans, elastin, laminin, fibronectin and casein [12]. It has been reported that MMP-7 was overexpressed both in benign and malignant colorectal tumors [13] [14] but the level of expression in colorectal cancer was known to be 50-fold greater than normal mucosa [15]. It has also been reported that MMP-7 was associated in the development and progression of CRC, and correlates with distant and lymph node metastasis [16] [17].

Vascular endothelial growth factor (VEGF) plays a critical role in the process of angiogenesis by stimulating the proliferation and migration of vascular endothelial cells, and modelling of the tumor neovasculature. Neoangiogenesis, mediated by angiogenic cytokines, contributes to the growth, progression and survival of tumors [18]. VEGF is a potent growth factor that stimulates a strong angiogenic response by increasing microvascular permeability [19]. The formation of new blood capillaries provides nutrients for rapid growth, and increases the opportunity for tumor cells to metastasize [18]. VEGF expression in CRC was found to be associated with poor prognosis and development of metastatic disease [20] [21], and could be an independent risk factor for tumor recurrence and might assist in selecting patients who could benefit from adjuvant therapy [22].

Currently colorectal malignancy is an important disease in Malaysia. The incidence of CRC is rising rapidly and ranked third highest in both males and females among the top ten most common cancers in Malaysia. It accounts for $14.2 \%$ of male cancers and $10.1 \%$ female cancers [23]. Although a number of etiological factors have been identified, the genetic information on the disease among the Malaysians is unavailable. Though STAT3, pSTAT3, MMP-7 and VEGF have been widely studied, in the present study we select these biomarkers to determine the expression pattern in colorectal adenocarcinomas using immunohistochemistry in a hospital-based Malaysian population. We also evaluate association with the clinico-pathological parameters such as patients' age, gender, ethnicity, histological grade, Dukes' stage and nodal status, and co-expression of these biomarkers.

\section{Materials and Methods}

\subsection{Patients and Tissues}

Colorectal adenocarcinomas were collected from 93 patients who underwent CRC resection at the Hospital Kuala Lumpur, Kuala Lumpur; Hospital Pulau Pinang, Pulau Pinang and Hospital University Kebangsaan Malaysia, Kuala Lumpur from 2003 to 2005 in Malaysia. Informed consent was obtained from the patients who were admitted for surgery. All the tissues were preserved in $10 \%$ buffered formalin and subsequently processed 
for histological evaluation and immunohistochemical studies. The clinico-pathological data including patients' gender, age, ethnic group, tumor grade and Dukes' stage were obtained from the surgical and pathological records of each patient (Table 1). The tumors were staged according to the Dukes' staging classification A, B, C and D. Tumors were histologically graded as well (Grade I), moderate (Grade II), and poorly (Grade III) differentiated based on the predominant pattern of the tumor by a qualified pathologist.

\subsection{Immunohistochemistry}

The tissue sections of $4 \mu \mathrm{m}$ thickness were cut from each paraffin-embedded tumor tissue blocks and placed on the glass slides. These blocks were obtained from the hospitals. These sections were immunostained with primary antibodies directed against STAT3 (rabbit anti-human, IgG H-190; polyclonal, Santa Cruz Biotechnology Inc., Santa Cruz, CA, USA), pSTAT3 (rabbit anti-human IgG Tyr705; polyclonal, Santa Cruz Biotechnology Inc., Santa Cruz, CA, USA), MMP-7 (rabbit anti-human, IgG/PUMP-1; polyclonal, Chemicon International, Temecula, CA, USA) and VEGF (mouse anti-human, IgG ${ }_{2 a}$ C-1; monoclonal, Santa Cruz Biotechnology Inc., Santa Cruz, CA, USA), using standard immunoperoxidase method. All the procedures were performed at room temperature, unless otherwise specified. DAKO Envision ${ }^{\mathrm{TM}}$, Peroxidase, Mouse kit (Dako, Glostrup, Denmark) was used to detect the reaction of mouse anti-human antibody for VEGF, and Dako Cytomation Envision System-HRP Labelled Polymer Anti-Rabbit (Dako, Glostrup, Denmark) was used to demonstrate the reaction of rabbit anti-human against STAT3, pSTAT3 and MMP-7 proteins.

The tissue sections were deparaffinized in xylene, rehydrated in decreasing concentration of ethanol and rinsed in distilled water. After a brief wash, the sections were subjected to microwave antigen retrieval treatment

Table 1. Clinico-pathological data of patients with colorectal adenocarcinoma.

\begin{tabular}{|c|c|}
\hline Patients' characteristic & Total number of cases $(\%)(\mathrm{N}=93)$ \\
\hline \multicolumn{2}{|l|}{ Age at diagnosis } \\
\hline$<60$ & $48(51.6)$ \\
\hline$>60$ & $45(48.4)$ \\
\hline \multicolumn{2}{|l|}{ Gender } \\
\hline Female & $31(33.3)$ \\
\hline Male & $62(66.7)$ \\
\hline \multicolumn{2}{|l|}{ Ethnicity } \\
\hline Malay & $29(31.2)$ \\
\hline Chinese & $53(57.0)$ \\
\hline Indian & $11(11.8)$ \\
\hline \multicolumn{2}{|l|}{ Histological grade } \\
\hline Grade I & $32(34.4)$ \\
\hline Grade II & $25(26.9)$ \\
\hline Grade III & $36(38.7)$ \\
\hline \multicolumn{2}{|l|}{ Dukes' stage } \\
\hline A & $9(9.7)$ \\
\hline B & $29(31.2)$ \\
\hline $\mathrm{C}$ & $39(41.9)$ \\
\hline $\mathrm{D}$ & $16(17.2)$ \\
\hline \multicolumn{2}{|l|}{ Lymph node status $(\mathrm{N})$} \\
\hline $\mathrm{N}^{+}$ & $55(59.1)$ \\
\hline $\mathrm{N}-$ & $38(40.9)$ \\
\hline
\end{tabular}


to obtain optimal staining intensity. The sections were microwaved in $10 \mathrm{mM}$ citrate buffer (pH 6.0) solution for STAT3, pSTAT3 and VEGF. The solution was allowed to boil for 5 minutes twice and then cooled down to the room temperature before washing the sections with the distilled water. Following the treatment, the sections were incubated with $3 \%$ hydrogen peroxide in water for 10 minutes at $37^{\circ} \mathrm{C}$ to block the endogeneous peroxidase activity. The slides were washed with distilled water and phosphate-buffered saline (PBS) pH 7.4 for 5 minutes each. The tissue sections were incubated with anti-STAT3 (dilution 1:150), anti-pSTAT3 (1:200), antiMMP-7 (1:50) and anti-VEGF (1:50) for 1 hour at room temperature in a humidified chamber. All the antibodies were diluted in 1\% BSA (bovine serum albumin, Sigma, St Louis, Missouri, USA). The slides were washed in PBS for 30 minutes. The sections were incubated with horseradish-peroxidase labelled polymer for $30 \mathrm{mi}-$ nutes at room temperature and rinsed with PBS for 5 minutes. The reactions were treated with DAB (3, 3 diaminobenzidine) chromogen (Dako, Glostrup, Denmark) until appropriate colour intensity was reached. The sections were counterstained with Harris haematoxylin for STAT3, pSTAT3, MMP-7 and VEGF by dipping for 4 seconds. The slides were mounted in Depex and examined under the light microscope (Leica, Germany). Colorectal carcinoma tissues positive for these markers were routinely used as positive controls. For negative control, the primary antibodies were substituted with PBS.

\subsection{Evaluation of Immunostaining and Statistical Analysis}

Tumor cells that exhibit cytoplasmic and/or nuclear immunoreactivity were considered as positive for STAT3 and pSTAT3. Immunostaining present in the cytoplasm of the malignant cells was regarded as positive for MMP-7 and VEGF protein expression. The scoring of the tissue sections was based on the percentage of the stained tumor cells [24]. The expression of STAT3, pSTAT3, MMP-7 and VEGF was based on the percentage of malignant cells stained: $0 \%-10 \%$ as negative; $11 \%$ - $25 \%$ as weakly positive, and equal or more than $26 \%$ as strongly positive or overexpressed. Weakly positive and negative tumors were not included in the statistical analysis.

All statistical analyses were carried out by using SPSS (version 11.5, USA). Association between expression of the biomarkers and clinico-pathological parameters was determined by nonparametric test. Since the normality of the data was violated, the nonparametric test namely Mann-Whitney for paired parameters (age at diagnosis, gender, lymph node status) or Kruskall-Willis for categorical data (ethnicity, histological grade, Dukes' stage) were used. The significance of co-expression of the biomarkers was analysed by Fisher's exact test. Statistical significance was set at $\mathrm{P}<0.05$.

\section{Results}

The immunostaining of STAT3 (Figure 1(a)) and pSTAT3 (Figure 1(b)) exhibited heterogeneous staining pattern. Expression of STAT3 was present either in the cytoplasm or nuclear region in colorectal tumor cells; occasional staining was present in both areas. However, pSTAT3 immunoreactivity appeared to be predominant in the nuclear region, whereas the cytoplasmic area showed very weak immunostaining. However, intratumor observation showed some heterogeneous immunoreactivity. MMP-7 (Figure 1(c)) and VEGF (Figure 1(d)) immunopositivity was detected in the cytoplasm of the tumor cells. Nuclear immunoreactivity was not noted in all the stained tumor cells. None of the stromal cells and negative control exhibited immunopositivity.

Overexpression of STAT3 was detected in 26.7\% (20/75), pSTAT3 in 13.4\% (10/75), MMP-7 in 38.8\% (36/93) and VEGF in 59.2\% (55/93) of CRCs. Tumors weakly positive for STAT3, pSTAT3, MMP-7 and VEGF were demonstrated in $1.3 \%$ (1/75), 1.3\% (1/75), 1.1\% (1/93) and 5.4\% (5/93) CRCs, respectively. Tumors were considered as negative for STAT3 in 72.0\% (54/75), pSTAT3 in 85.3\% (64/75), MMP-7 in 60.2\% (56/93) and VEGF in 35.5\% (33/93) of CRCs.

Statistical analysis was performed to evaluate the relationship between STAT3, pSTAT3, MMP-7 or VEGF immunoreactivity and clinico-pathological parameters such as patients' age, gender, ethnic group, histological grade, Dukes' stage and nodal status (Table 2 and Table 3). STAT3, MMP-7 and VEGF immunopositivity were significantly correlated with poorly-differentiated tumors $(\mathrm{P}=0.004 ; \mathrm{P}=0.03 ; \mathrm{P}=0.002$, respectively) but not with other parameters. However, pSTAT3 immunostaining was not significantly associated with the clinico-pathological characteristics. Elevated expression of STAT3, MMP-7 and VEGF was demonstrated in 44.8\%, $41.7 \%$ and $72.2 \%$ of the poorly-differentiated tumors, and $30.0 \%, 56.0 \%$ and $72.0 \%$ of the moderately-differentiated tumors compared to $3.8 \%, 21.9 \%$ and $34.4 \%$ of the well-differentiated tumors, correspondingly. 

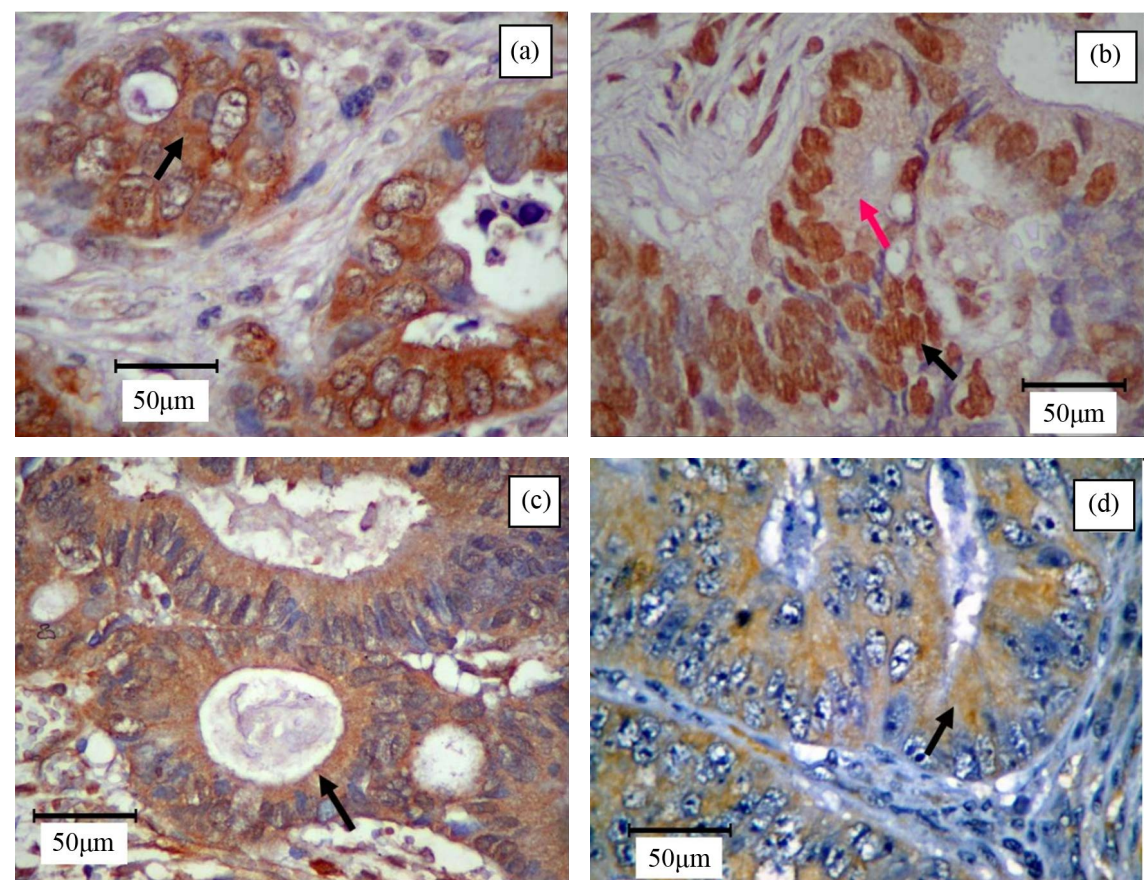

Figure 1. Immunohistochemistry of poorly (a), moderately (b), (c) and well (d) differentiated colorectal adenocarcinoma. Immunostaining of (a) STAT3 was noted predominantly in the cytoplasm of the epithelial cells (arrow); (b) pSTAT3 was demonstrated as co-existence of intense nuclear (black arrow) and very light cytoplasmic (pink arrow) staining of the epithelial cells; (c) MMP-7 was observed as a prominent cytoplasmic staining in the neoplastic colonic-epithelium (arrow); and (d) VEGF was shown as predominant cytoplasmic staining in the glandular tissue (arrow). Original magnification, $\times 400$.

Co-expression between STAT3, pSTAT3, MMP-7 and VEGF genes was also analysed (Table 4). Significant relationship was noted between overexpression of pSTAT3 and STAT3 $(\mathrm{P}<0.001)$, pSTAT3 and VEGF $(\mathrm{P}=$ 0.044), pSTAT3 and MMP-7 ( $\mathrm{P}=0.003)$, and STAT3 and VEGF $(\mathrm{P}=0.037)$ but marginal association was detected between STAT3 and MMP-7 $(\mathrm{P}=0.057)$, and MMP-7 and VEGF $(\mathrm{P}=0.052)$.

\section{Discussion}

In the present study we have examined the expression of STAT3, pSTAT3, MMP-7 and VEGF protein by immunohistochemistry in a cohort of colorectal adenocarcinomas. There was overexpression of STAT3 in 26.7\% of CRCs but smaller proportion (13.4\%) of the tumors demonstrated the activated form of STAT3 (pSTAT3). Similarly Hbibi et al. noted that $62 \%$ and $27 \%$ of 126 CRCs were positive for STAT3 and pSTAT3, respectively [25]. Other investigators reported that the frequencies of overexpressed tumors range from 44\% - 78\% [4] [8] [9] [26] [27]. Interestingly, Xiong et al. reported 100\% immunopositivity for both STAT3 and pSTAT3 protein in 38 cases [28]. Significant correlation was noted between increased expression of STAT3 and the phosphorylated form of STAT3 which is in agreement with findings by Lassman et al. [29]. Interestingly our data showed lower frequency of pSTAT3 overexpression among the CRCs compared to other findings which could be attributed to scoring methods, random selection of patients and types of antibodies used. Our findings suggest that a proportion of the tumors that overexpress STAT3 might harbour higher levels of pSTAT3 which could have important implications in colorectal cancer biology.

Increased expression of STAT3 was significantly associated with high grade tumors but this was not seen for the phosphorylated form of STAT3. Although the association was not supported statistically, higher frequency of poorly-differentiated tumors $(24.1 \%)$ was positive for pSTAT3 compared to moderately $(10.0 \%)$ and well (3.8\%) differentiated tumors. Overexpression of STAT3 and pSTAT3 was not associated with other clinico-pathological parameters such as age, gender, ethnicity, Dukes' classification and nodal metastases. Contrary to our results, some studies showed significant correlation between PSTAT3 and presence of nodal metastases [4] [9] 
Table 2. Association between positive expression of STAT3 or pSTAT3 and clinico-pathological features in colorectal adenocarcinoma patients.

\begin{tabular}{|c|c|c|c|c|c|}
\hline $\begin{array}{l}\text { Clinico-pathological } \\
\text { features }\end{array}$ & $\begin{array}{l}\text { Total number of } \\
\text { cases }(n=75)\end{array}$ & $\begin{array}{l}\text { Number positive cases for } \\
\text { STAT3 }(\%)(\mathrm{n}=20)\end{array}$ & $\mathrm{P}^{*}$ value & $\begin{array}{l}\text { Number positive cases for } \\
\text { pSTAT3 }(\%)(\mathrm{n}=10)\end{array}$ & $\mathrm{P}^{*}$ value \\
\hline \multicolumn{6}{|l|}{ Patients' age (years) } \\
\hline$<60$ & 23 & $5(21.7)$ & 0.375 (NS) & $3(13.0)$ & $0.814(\mathrm{NS})$ \\
\hline$>60$ & 52 & $15(28.8)$ & & $7(13.5)$ & \\
\hline \multicolumn{6}{|l|}{ Gender } \\
\hline Female & 35 & $11(31.4)$ & 0.507 (NS) & $4(11.4)$ & 0.576 (NS) \\
\hline Male & 40 & $9(22.5)$ & & $6(15.0)$ & \\
\hline \multicolumn{6}{|l|}{ Ethnicity } \\
\hline Malay & 25 & $6(24.0)$ & 0.941 (NS) & $4(9.3)$ & 0.818 (NS) \\
\hline Chinese & 43 & $12(27.9)$ & & $5(20.0)$ & \\
\hline Indian & 7 & $2(28.6)$ & & $1(14.3)$ & \\
\hline \multicolumn{6}{|l|}{ Histological grade } \\
\hline Grade I & 26 & $1(3.8)$ & $0.004(\mathrm{~S})$ & $1(3.8)$ & 0.086 (NS) \\
\hline Grade II & 20 & $6(30.0)$ & & $2(10.0)$ & \\
\hline Grade III & 29 & $13(44.8)$ & & $7(24.1)$ & \\
\hline \multicolumn{6}{|l|}{ Dukes’ stage } \\
\hline A & 5 & $0(0)$ & 0.435 (NS) & $0(0)$ & $0.064(\mathrm{NS})$ \\
\hline B & 24 & $7(29.2)$ & & $2(8.3)$ & \\
\hline $\mathrm{C}$ & 32 & $9(28.1)$ & & $8(25.0)$ & \\
\hline $\mathrm{D}$ & 14 & $4(28.6)$ & & $0(0)$ & \\
\hline \multicolumn{6}{|l|}{ Lymph node status (N) } \\
\hline $\mathrm{N}+$ & 46 & $13(28.3)$ & 0.550 (NS) & $8(17.4)$ & 0.158 (NS) \\
\hline $\mathrm{N}-$ & 29 & 7 (24.1) & & $2(6.9)$ & \\
\hline
\end{tabular}

${ }^{*}$ Represents significance at $\mathrm{P}<0.05$; Note: S, significant at $\mathrm{P}<0.05$. NS, not significant.

[25] [27] and advanced Dukes' stage [8] [27] but not with age, gender and/or tumor grade [4] [9] [27]. In a recent study, Xiong et al. showed that all the well $(n=6)$, moderately $(n=27)$ and poorly-differentiated $(n=3)$ tumors were positive for both the activated and unactivated form of STAT3 protein [28]. Though constrasting results were noted probably due to smaller sample size, our data suggests that upregulation of STAT3 and pSTAT3 in CRC could have an important role in the tumor progression as defined by its association with high grade tumors.

MMP-7 is widely expressed in the epithelial tumor cells of malignant colorectal adenocarcinomas and believed to be associated with metastasis [13] [14] [30] [31]. In the current study we found that MMP-7 was overexpressed in 38.8\% of CRCs and this positive rate is comparable with previous reports of 30\% to $46 \%$ [15] [17] [30] [32]. In a recent study with a larger sample size of 620 cases, Fang et al. reported MMP-7 immunopositivity in $88.8 \%$ of the cancer [33]. Roca and co-investigators demonstrated $81.7 \%$ of 60 CRC tumors were positive for MMP-7 [34]. In the present study, clinico-pathological analysis demonstrated that the frequency of MMP-7 immunopositivity was significantly higher in moderately- and poorly-differentiated tumors compared to welldifferentiated tumors. However, earlier studies did not observe such association [17] [34]. Some of the studies have evaluated expression of MMP-7 in association with clinico-pathological parameters but did not correlate with histological grade [15] [30] [32] [33]. There was no significant association between MMP-7 expression and 
Table 3. Association between positive expression of MMP-7 or VEGF and clinico-pathological features in colorectal adenocarcinoma patients.

\begin{tabular}{|c|c|c|c|c|c|}
\hline $\begin{array}{l}\text { Clinico-pathological } \\
\text { features }\end{array}$ & $\begin{array}{l}\text { Total number } \\
\text { of cases }(n=93)\end{array}$ & $\begin{array}{l}\text { Number positive cases for } \\
\text { MMP-7 }(\%)(n=36)\end{array}$ & $\mathrm{P}^{*}$ value & $\begin{array}{l}\text { Number positive cases for } \\
\text { VEGF }(\%)(\mathrm{n}=55)\end{array}$ & $\mathrm{P}^{*}$ value \\
\hline \multicolumn{6}{|l|}{ Patients' age (years) } \\
\hline$<60$ & 31 & $8(25.8)$ & 0.072 (NS) & $18(58.0)$ & 0.882 (NS) \\
\hline$>60$ & 62 & $28(45.2)$ & & 37 (59.7) & \\
\hline \multicolumn{6}{|l|}{ Gender } \\
\hline Female & 45 & $19(42.2)$ & 0.503 (NS) & $28(62.2)$ & 0.560 (NS) \\
\hline Male & 48 & $17(35.4)$ & & 27 (56.3) & \\
\hline \multicolumn{6}{|l|}{ Ethnicity } \\
\hline Malay & 29 & $11(37.9)$ & 0.975 (NS) & 15 (51.7) & 0.620 (NS) \\
\hline Chinese & 53 & $21(39.6)$ & & 33 (62.3) & \\
\hline Indian & 11 & $4(36.4)$ & & 7 (63.6) & \\
\hline \multicolumn{6}{|l|}{ Histological grade } \\
\hline Grade I & 32 & 7 (21.9) & $0.030(\mathrm{~S})$ & $11(34.4)$ & $0.002(\mathrm{~S})$ \\
\hline Grade II & 25 & $14(56.0)$ & & $18(72.0)$ & \\
\hline Grade III & 36 & 15 (41.7) & & $26(72.2)$ & \\
\hline \multicolumn{6}{|l|}{ Dukes' stage } \\
\hline A & 9 & $3(33.3)$ & 0.186 (NS) & $4(44.4)$ & 0.477 (NS) \\
\hline B & 29 & 15 (51.7) & & $20(69.0)$ & \\
\hline $\mathrm{C}$ & 39 & 15 (38.5) & & $23(59.0)$ & \\
\hline $\mathrm{D}$ & 16 & $3(18.8)$ & & $8(50.0)$ & \\
\hline \multicolumn{6}{|l|}{ Lymph node status (N) } \\
\hline $\mathrm{N}+$ & 55 & 18 (32.7) & 0.156 (NS) & $31(56.4)$ & 0.515 (NS) \\
\hline $\mathrm{N}^{-}$ & 38 & $18(47.4)$ & & $24(63.2)$ & \\
\hline
\end{tabular}

"Represents significance at $\mathrm{P}<0.05$; Note: $\mathrm{S}$, significant at $\mathrm{P}<0.05$. NS, not significant.

Table 4. Association between STAT3, pSTAT3, MMP-7 and VEGF protein expression in colorectal adenocarcinoma patients.

\begin{tabular}{|c|c|c|c|c|c|}
\hline & $\begin{array}{l}\text { Total number } \\
\text { of cases }\end{array}$ & $\begin{array}{l}\text { Positive }(+) / \\
\text { negative }(-)\end{array}$ & $\begin{array}{c}\text { Number positive cases for } \\
\text { pSTAT3 (\%) }\end{array}$ & $\begin{array}{l}\text { Number positive cases } \\
\text { for MMP-7 (\%) }\end{array}$ & $\begin{array}{l}\text { Number positive cases } \\
\text { for VEGF (\%) }\end{array}$ \\
\hline \multirow{4}{*}{ STAT3 } & $(n=75)$ & & $(n=10)$ & $(\mathrm{n}=27)$ & $(n=45)$ \\
\hline & 20 & + & $8(40.0)$ & $11(55.0)$ & $16(80.0)$ \\
\hline & 55 & - & $2(3.6)$ & $16(29.1)$ & 29 (52.7) \\
\hline & & & $\mathrm{P}<0.001(\mathrm{~S})$ & $\mathrm{P}=0.057(\mathrm{NS})$ & $\mathrm{P}=0.037(\mathrm{~S})$ \\
\hline \multirow{4}{*}{ pSTAT3 } & $(n=75)$ & & & $(n=27)$ & $(n=45)$ \\
\hline & 10 & + & - & $8(80.0)$ & $9(90.0)$ \\
\hline & 65 & - & & 19 (23.1) & $36(55.4)$ \\
\hline & & & & $\mathrm{P}=0.003(\mathrm{~S})$ & $\mathrm{P}=0.044(\mathrm{~S})$ \\
\hline \multirow{4}{*}{ MMP-7 } & $(\mathrm{n}=93)$ & & & & $(\mathrm{n}=55)$ \\
\hline & 36 & + & & & $26(72.2)$ \\
\hline & 57 & - & - & - & 29 (50.9) \\
\hline & & & & & $\mathrm{P}=0.052(\mathrm{NS})$ \\
\hline
\end{tabular}

Note: S, significant at $\mathrm{P}<0.05$. NS, not significant. 
the age, gender, ethnicity, Dukes' staging and lymph node status of the patients. Roca and coauthors found no significant correlation between MMP-7 and lymph node metastases which is consistent with our findings [34]. In contrast, Adachi and co-investigators reported that elevated levels of MMP-7 was significantly associated with lymph node metastases and advanced Dukes' stage suggesting its role in tumor metastases [15] [30]. Our findings suggest that overexpression of MMP-7 could be a biological indicator for aggressive characteristics of colorectal cancer.

VEGF has been extensively investigated in relation to the development of novel drugs against CRCs [20]. In the current study, elevated levels of VEGF were demonstrated in 59.2\% of CRC. Among the biomarkers evaluated in this study, VEGF immunopositivity was the most frequent in CRC. In a series of studies, overexpression of VEGF was detected in 45\% to 70\% of CRCs [21] [35]-[42] which is comparable with the present study. However, Khorana et al. reported lower incidence of VEGF immunopositivity (34\%) [43] whereas Uner et al. showed higher frequency of $86 \%$ in CRCs [44]. In the present study, a significant association was observed between VEGF expression and high histological grade tumors. Although consistent with other published reports [40] [42], majority of the studies did not confirm the association [21] [35]-[39] [41] [44] [45]. Statistical correlation was not found with Dukes' stage and lymph node involvement which is in agreement with other reports [37] [44] [46]. However most of the studies have demonstrated significant correlation between VEGF immunoreactivity and nodal metastases [21] [36] [39] [40] [42] [45] or advanced Dukes' stage [36]. The patients' characteristics (age at diagnosis, gender and ethnicity) were not significantly associated with VEGF expression and similar observation was also noted by other investigators [21] [35] [36] [38] [39] [41] [42] [45] [46]. Our observation suggests that overexpression of VEGF could be an important marker for aggressive phenotype of colorectal tumors.

Apart from determining the frequencies of the genes overexpressed as well as correlation with clinico-pathological parameters we also determined co-overexpression of STAT3, pSTAT3, MMP-7 and VEGF in CRCs. Overexpression of STAT3 was significantly associated with VEGF but showed marginal correlation with MMP-7. However, the activated form of STAT3 was found to be significantly associated with MMP-7 and VEGF. Our data also showed that elevated levels of MMP-7 was marginally associated VEGF. Earlier studies have reported that pSTAT3 promotes tumor angiogenesis by acting as a direct transcriptional activator of VEGF and mediates expression of genes related to tumor growth and metastasis [6]. Recently, Cascio and co-investigators supported this evidence in colon cancer cells by demonstrating the binding of STAT3 to the promoter of VEGF [47]. Elevated levels of MMP-7 mRNA was detected in colorectal tumor tissues with activated form of STAT3 [3]. In addition to MMP-7, aberrant activity of STAT3 could be a major factor of local tumor progression and metastasis of colorectal cancer through upregulation of other MMPs including MMP-1, MMP-3 and MMP-9 [3]. This could also explain the reason that we noted pSTAT3 was significantly associated with MMP-7 but STAT3 showed marginal association with MMP-7.

Among the MMPs (MMP-1, MMP-2, MMP-3, MMP-7, MMP-9 and MMP-13), MMP-7 is primarily expressed in cancer cells during tumor progression [48] and implicated in promoting angiogenesis by remodeling the ECM [49]. Ito et al. reported that despite increased expression of VEGF, upregulation of MMP-7 in addition to MMP-1 and MMP-3 may regulate the switch from vascular quiescence to angiogenesis in the human colorectal tissues [50]. Furthermore, high levels of MMP-7, MMP-1 and MMP-3 along with VEGF is associated with increased expression of angiogenesis markers in the CRC suggesting that MMP-7 could be one of the regulators of VEGF activity in human colorectal cancer cells. These observations support our data that demonstrated marginal association between MMP-7 and VEGF.

The possible reasons for the differences between the studies could be attributed to the sample size of the cases used in the investigations, scoring methods including variations in the threshold definitions for overexpression between the laboratories, selection bias with regard to recruitment of patients such as patients' characteristics, ethnicity, different histopathological types of the tumors and antibodies used. These differences could alter the distribution of the immunopositivity that might influence the statistical power to determine the significance of association.

In our study, we showed an interesting observation that STAT3, MMP-7 and VEGF were consistently associated with high grade tumors. Histological grade or tumor differentiation has been regarded as one of the predictive factors associated with poor prognosis for colorectal carcinomas. Furthermore we have also demonstrated significant correlation between pSTAT3 and VEGF or MMP-7, with marginal association between VEGF and MMP-7. 


\section{Conclusion}

In conclusion, our data suggest that expression of these genes may have an important role in tumor dedifferentiation and may be useful indicators of biologic aggressiveness. Co-expression of the biomarkers by cancer cells might have important implications in colorectal cancer biology and could be useful biological markers of the malignant phenotype.

\section{Acknowledgements}

This study was financially supported by National Biotechnology Directorate, Medical Biotechnology Cooperative Centre, Ministry of Science, Technology and Innovation, Malaysia.

\section{Conflict of Interest}

The authors declare that they have no conflict of interest related to the publication of this manuscript.

\section{References}

[1] Levy, D.E. and Darnell Jr., J.E. (2002) Stats: Transcriptional Control and Biological Impact. Nature Reviews Molecular Cell Biology, 3, 651-662. http://dx.doi.org/10.1038/nrm909

[2] Bromberg, J. (2002) Stat Proteins and Oncogenesis. Journal of Clinical Investigation, 109, 1139-1142. http://dx.doi.org/10.1172/JCI0215617

[3] Tsareva, S.A., Moriggl, R., Corvinus, F.M., Wiederanders, B., Schütz, A., Kovacic, B. and Friedrich, K. (2007) Signal Transducer and Activator of Transcription 3 Activation Promotes Invasive Growth of Colon Carcinomas through Matrix Metalloproteinase Induction. Neoplasia, 9, 279-291. http://dx.doi.org/10.1593/neo.06820

[4] Ma, X.T., Wang, S., Ye, Y.J., Du, R.Y., Cui, Z.R. and Somsouk, M. (2004) Constitutive Activation of Stat3 Signaling Pathway in Human Colorectal Carcinoma. World Journal of Gastroenterology, 10, 1569-1573.

[5] Bowman, T., Garcia, R., Turkson, J. and Jove, R. (2000) STATs in Oncogenesis. Oncogene, 19, 2474-2488. http://dx.doi.org/10.1038/sj.onc.1203527

[6] Niu, G., Wright, K.L., Huang, M., Song, L., Haura, E., Turkson, J., Zhang, S., Wang, T., Sinibaldi, D., Loppola, D., Heller, R., Ellis, L.M., Karras, J., Bromberg, J., Pardoll, D., Jove, R. and Yu, H. (2002) Constitutive Stat3 Activity Up-Regulates VEGF Expression and Tumor Angiogenesis. Oncogene, 21, 2000-2008. http://dx.doi.org/10.1038/sj.onc.1205260

[7] Real, P.J., Sierra, A., De Juan, A., Segovia, J.C., Lopez-Vega, J.M. and Fernandez-Luna, J.L. (2002) Resistance to Chemotherapy via Stat3-Dependent Overexpression of Bcl-2 in Metastatic Breast Cancer Cells. Oncogene, 21, 76117668. http://dx.doi.org/10.1038/sj.onc.1206004

[8] Kusaba, T., Nakayama, T., Yamazumi, K., Yakata, Y., Yoshizaki, A., Inoue, K., Nagayasu, T. and Sekine, I. (2006) Activation of STAT3 Is a Marker of Poor Prognosis in Human Colorectal Cancer. Oncology Reports, 15, 1445-1451.

[9] Park, J.K., Hong, R., Kim, K.J., Lee, T.B. and Lim, S.C. (2008) Significance of p-STAT3 Expression in Human Colorectal Adenocarcinoma. Oncology Reports, 20, 597-604.

[10] Curran, S. and Murray, G.I. (2000) Matrix Metalloproteinases: Molecular Aspects of Their Roles in Tumour Invasion and Metastasis. European Journal of Cancer, 36, 1621-1630. http://dx.doi.org/10.1016/S0959-8049(00)00156-8

[11] Stetler-Stevenson, W.G., Hewitt, R. and Corcoran, M. (1996) Matrix Metalloproteinases and Tumour Invasion: From Correlation and Causality to the Clinic. Seminar Cancer Biology, 7, 147-154. http://dx.doi.org/10.1006/scbi.1996.0020

[12] Wilson, C.L. and Matrisian, L.M. (1996) Matrilysin: An Epithelial Matrix Metalloproteinase with Potentially Novel Functions. International Journal of Biochemistry and Cell Biology, 28, 123-136. http://dx.doi.org/10.1016/1357-2725(95)00121-2

[13] Newell, K.J., Witty, J.P., Rodgers, W.H. and Matrisian, L.M. (1994) Expression and Localization of Matrix-Degrading Metalloproteinases during Colorectal Tumorigenesis. Molecular Carcinogenesis, 10, 199-206. http://dx.doi.org/10.1002/mc.2940100404

[14] Ishikawa, T., Ichikawa, Y., Mitsuhashi, M., Momiyama, N., Chishima, T., Tanaka, K., Yamaoka, H., Miyazakic, K., Nagashima, Y., Akitaya, T. and Shimada, H. (1996) Matrilysin Is Associated with Progression of Colorectal Tumor. Cancer Letters, 107, 5-10. http://dx.doi.org/10.1016/0304-3835(96)04336-4

[15] Adachi, Y., Yamamoto, H., Itoh, F., Arimura, Y., Nishi, M., Endo, T. and Imai, K. (2001) Clinicopathologic and Prognostic Significance of Matrilysin Expression at the Invasive Front in Human Colorectal Cancers. International Journal of Cancer, 95, 290-294. 
[16] Masaki, T., Sugiyama, M., Matsuoka, H., Abe, N., Izumisato, Y., Sakamoto, A. and Atomi, Y. (2003) Matrix Metalloproteinases May Contribute Compensationally to Tumor Invasion in T1 Colorectal Carcinomas. Anticancer Research, 23, 4169-4173.

[17] Masaki, T., Matsuoka, H., Sugiyama, M., Abe, N., Goto, A., Sakamoto, A. and Atomi, Y. (2001) Matrilysin (MMP-7) as a Significant Determinant of Malignant Potential of Early Invasive Colorectal Carcinomas. British Journal of Cancer, 84, 1317-1321. http://dx.doi.org/10.1054/bjoc.2001.1790

[18] Hanahan, D. and Folkman, J. (1996) Patterns and Emerging Mechanisms of the Angiogenic Switch during Tumorigenesis. Cell, 86, 353-364. http://dx.doi.org/10.1016/S0092-8674(00)80108-7

[19] Dvorak, H.F., Detmar, M., Claffey, K.P., Nagy, J.A., van de Water, L. and Senger, D.R. (1995) Vascular Permeability Factor/Vascular Endothelial Growth Factor: An Important Mediator of Angiogenesis in Malignancy and Inflammation. International Archives of Allergy and Immunology, 107, 233-235. http://dx.doi.org/10.1159/000236988

[20] Guba, M., Seeliger, H., Kleespies, A., Jauch, K.W. and Bruns, C. (2004) Vascular Endothelial Growth Factor in Colorectal Cancer. International Journal of Colorectal Disease, 19, 510-517. http://dx.doi.org/10.1007/s00384-003-0576-y

[21] Zafirellis, K., Agrogiannis, G., Zachaki, A., Gravani, K., Karameris, A. and Kombouras, C. (2008) Prognostic Significance of VEGF Expression Evaluated by Quantitative Immunohistochemical Analysis in Colorectal Cancer. Journal of Surgical Research, 147, 99-107. http://dx.doi.org/10.1016/j.jss.2007.05.041

[22] Altomare, D.F., Rotelli, M.T., Pentimone, A., Rossiello, M.R., Martinelli, E., Guglielmi, A., De Fazio, M., Marino, F., Memeo, V., Colucci, M. and Semeraro, N. (2007) Tissue Factor and Vascular Endothelial Growth Factor Expression in Colorectal Cancer: Relation with Cancer Recurrence. Colorectal Disease, 9, 133-138. http://dx.doi.org/10.1111/j.1463-1318.2006.01158.x

[23] Lim, G.C.C. and Halimah, Y. (2004) Second Report of the National Cancer Registry. Cancer Incidence in Malaysia 2003. National Cancer Registry, Lumpur.

[24] Madbouly, K.M., Senagore, A.J., Mukerjee, A., Delaney, C.P., Connor, J. and Fazio, V.W. (2007) Does Immunostaining Effectively Upstage Colorectal Cancer by Identifying Micrometastatic Nodal Disease? International Journal of Colorectal Disease, 22, 39-48. http://dx.doi.org/10.1007/s00384-006-0098-5

[25] Hbibi, A.T., Lagorce, C., Wind, P., Spano, J.P., Guetz, G., Milano, G., Benamouzig, R., Rixe, O., Morere, J.F., Breau, J.L., Martin, A. and Fagard, R. (2008) Identification of a Functional EGF-R/p60c-src/STAT3 Pathway in Colorectal Carcinoma: Analysis of Its Long-Term Prognostic Value. Cancer Biomarkers, 4, 83-91.

[26] Kawada, M., Seno, H., Uenoyama, Y., Sawabu, T., Kanda, N., Fukui, H., Shimahara, Y. and Chiba, T. (2006) Signal Transducers and Activators of Transcription 3 Activation Is Involved in Nuclear Accumulation of Beta-Catenin in Colorectal Cancer. Cancer Research, 66, 2913-2917. http://dx.doi.org/10.1158/0008-5472.CAN-05-3460

[27] Kusaba, T., Nakayama, T., Yamazumi, K., Yakata, Y., Yoshizaki, A., Nagayasu, T. and Sekine, I. (2005) Expression of p-STAT3 in Human Colorectal Adenocarcinoma and Adenoma; Correlation with Clinicopathological Factors. Journal of Clinical Pathology, 58, 833-838. http://dx.doi.org/10.1136/jcp.2004.023416

[28] Xiong, H., Zhang, Z.G., Tian, X.Q., Sun, D.F., Liang, Q.C., Zhang, Y.J., Lu, R., Chen, Y.X. and Fang, J.Y. (2008) Inhibition of JAK1, 2/STAT3 Signaling Induces Apoptosis, Cell Cycle Arrest, and Reduces Tumor Cell Invasion in Colorectal Cancer Cells. Neoplasia, 10, 287-297.

[29] Lassmann, S., Schuster, I., Walch, A., Göbel, H., Jütting, U., Makowiec, F., Hopt, U. and Werner, M. (2007) STAT3 mRNA and Protein Expression in Colorectal Cancer: Effects on STAT3-Inducible Targets Linked to Cell Survival and Proliferation. Journal of Clinical Pathology, 60, 173-179. http://dx.doi.org/10.1136/jcp.2005.035113

[30] Adachi, Y., Yamamoto, H., Itoh, F., Hinoda, Y., Okada, Y. and Imai, K. (1999) Contribution of Matrilysin (MMP-7) to the Metastatic Pathway of Human Colorectal Cancers. Gut, 45, 252-258. http://dx.doi.org/10.1136/gut.45.2.252

[31] Remy, L., Trespeuch, C., Bachy, S., Scoazec, J.Y. and Rousselle, P. (2006) Matrilysin 1 Influences Colon Carcinoma Cell Migration by Cleavage of the Laminin-5 $\beta 3$ Chain. Cancer Research, 66, 11228-11237. http://dx.doi.org/10.1158/0008-5472.CAN-06-1187

[32] Jeffery, N., McLean, M.H., El-Omar, E.M. and Murray, G.I. (2009) The Matrix Metalloproteinase/Tissue Inhibitor of Matrix Metalloproteinase Profile in Colorectal Polyp Cancers. Histopathology, 4, 820-828. http://dx.doi.org/10.1111/j.1365-2559.2009.03301.X

[33] Fang, Y.J., Lu, Z.H., Wang, G.Q., Pan, Z.Z., Zhou, Z.W., Yun, J.P., Zhang, M.F. and Wan, D.S. (2009) Elevated Expressions of MMP7, TROP2, and Survivin Are Associated with Survival, Disease Recurrence, and Liver Metastasis of Colon Cancer. International Journal of Colorectal Disease, 24, 875-884. http://dx.doi.org/10.1007/s00384-009-0725-Z

[34] Roca, F., Mauro, L.V., Morandi, A., Bonadeo, F., Vaccaro, C., Quintana, G.O., Specterman, S., Joffé, E.B.K., Pallotta, M.Q., Puricelli, L.I. and Lastiri, J. (2006) Prognostic Value of E-Cadherin, $\beta$-Catenin, MMPs (7 and 9), and TIMPs (1 and 2) in Patients with Colorectal Carcinoma. Journal of Surgical Oncology, 93, 151-160. http://dx.doi.org/10.1002/jso.20413 
[35] Barresi, V., Di Gregorio, C., Regiani-Bonetti, L., Leon, M., Barresi, G. and Vitarelli, E. (2010) Stage I Colorectal Carcinoma: VEGF Immunohistochemical Expression, Microvessel Density, and Their Correlation with Clinical Outcome. Virchows Archiv, 457, 11-19. http://dx.doi.org/10.1007/s00428-010-0933-5

[36] Yin, Y., Cao, L.Y., Wu, W.Q., Li, H., Jiang, Y. and Zhang, H.F. (2010) Blocking Effects of siRNA on VEGF Expression in Human Colorectal Cancer Cells. World Journal of Gastroenterology, 16, 1086-1092. http://dx.doi.org/10.3748/wjg.v16.i9.1086

[37] Kwon, H.C., Kim, S.H., Oh, S.Y., Lee, S., Kwon, K.A., Lee, J.H., Choi, H.J., Park, K.J., Lee, H.S., Roh, M.S. and Kim, H.J. (2010) Clinicopathological Significance of Nuclear Factor- $\kappa$ B, HIF-1 $\alpha$, and Vascular Endothelial Growth Factor Expression in Stage III Colorectal Cancer. Cancer Science, 10, 1557-1561. http://dx.doi.org/10.1111/j.1349-7006.2010.01553.x

[38] Ljujic, B., Radosavljevic, G., Jovanovic, I., Pavlovic, S., Zdravkovic, N., Milovanovic, M., Acimovic, L., Knezevic, M., Bankovic, D., Zdravkovic, D. and Arsenijevic, N. (2010) Elevated Serum Level of IL-23 Correlates with Expression of VEGF in Human Colorectal Carcinoma. Archive of Medical Research, 41, 182-189. http://dx.doi.org/10.1016/j.arcmed.2010.02.009

[39] Cao, D., Hou, M., Guan, Y.S., Jiang, M., Yang, Y. and Gou, H.F. (2009) Expression of HIF-1 $\alpha$ and VEGF in Colorectal Cancer: Association with Clinical Outcomes and Prognostic Implications. BMC Cancer, 9, 432. http://dx.doi.org/10.1186/1471-2407-9-432

[40] Doger, F.K., Meteoglu, I., Tuncyurek, P., Okyay, P. and Cevikel, H. (2006) Does the EGFR and VEGF Expression Predict the Prognosis in Colon Cancer? European Surgical Research, 38, 540-544. http://dx.doi.org/10.1159/000096774

[41] Noike, T., Miwa, S., Soeda, J., Kobayashi, A. and Miyagawa, S. (2008) Increased Expression of Thioredoxin-1, Vascular Endothelial Growth Factor, and Redox Factor-1 Is Associated with Poor Prognosis in Patients with Liver Metastasis from Colorectal Cancer. Human Pathology, 39, 201-208. http://dx.doi.org/10.1016/j.humpath.2007.04.024

[42] Zhang, C., Hao, L., Wang, L., Xiao, Y., Ge, H., Zhu, Z., Luo, Y. and Zhang, Y. (2010) Elevated IGFIR Expression Regulating VEGF and VEGF-C Predicts Lymph Node Metastasis in Human Colorectal Cancer. BMC Cancer, 10, 184. http://dx.doi.org/10.1186/1471-2407-10-184

[43] Khorana, A.A., Ryan, C.K., Cox, C., Eberly, S. and Sahasrabudhe, D.M. (2003) Vascular Endothelial Growth Factor, CD68, and Epidermal Growth Factor Receptor Expression and Survival in Patients with Stage II and Stage III Colon Carcinoma: A Role for the Host Response in Prognosis. Cancer, 97, 960-968. http://dx.doi.org/10.1002/cncr.11152

[44] Uner, A., Ebinc, F.A., Akyurek, N., Unsal, D., Mentes, B.B. and Dursun, A. (2005) Vascular Endothelial Growth Factor, c-erbB-2 and c-erbB-3 Expression in Colorectal Adenoma and Adenocarcinoma. Experimental Oncology, 27, 225228.

[45] Ottaiano, A., Franco, R., Talamanca, A., Liguori, G., Tatangelo, F., Delrio, P., Nasti, G., Barletta, E., Facchini, G., Daniele, B., Di Blasi, A., Napolitano, M., Ieranò, C., Calemma, R., Leonardi, E., Albino, V., De Angelis, V., Falanga, M., Boccia, V., Capuozzo, M., Parisi, V., Botti, G., Castello, G., Iaffaioli, V.R. and Scala, S. (2006) Overexpression of both CXC Chemokine Receptor 4 and Vascular Endothelial Growth Factor Proteins Predicts Early Distant Relapse in Stage II-III Colorectal Cancer Patients. Clinical Cancer Research, 12, 2795-2803. http://dx.doi.org/10.1158/1078-0432.CCR-05-2142

[46] Dassoulas, K., Gazouli, M., Theodoropoulos, G., Christoni, Z., Rizos, S., Zisi-Serbetzoglou, A., et al. (2010) Vascular Endothelial Growth Factor and Endoglin Expression in Colorectal Cancer. Journal of Cancer Research Clinical Oncology, 136, 703-708. http://dx.doi.org/10.1007/s00432-009-0709-y

[47] Cascio, S., Ferla, R., D’Andrea, A., Gerbino, A., Bazan, V., Surmacz, E. and Russo, A. (2009) Expression of Angiogenic Regulators, VEGF and Leptin, Is Regulated by the EGF/PI3K/STAT3 Pathway in Colorectal Cancer Cells. Journal of Cell Physiology, 221, 189-194. http://dx.doi.org/10.1002/jcp.21843

[48] Overall, C.M. and Kleifeld, O. (2006) Validating Matrix Metalloproteinases as Drug Targets and Anti-Targets for Cancer Therapy. Nature Review Cancer, 6, 227-239. http://dx.doi.org/10.1038/nrc1821

[49] Roy, R., Zhan, B. and Moses, M.A. (2006) Making the Cut: Protease-Mediated Regulation of Angiogenesis. Experimental Cell Research, 312, 608-622. http://dx.doi.org/10.1016/j.yexcr.2005.11.022

[50] Ito, T.K., Ishii, G., Chiba, H. and Ochiai, A. (2007) The VEGF Angiogenic Switch of Fibroblasts Is Regulated by MMP-7 from Cancer Cells. Oncogene, 26, 7194-7203. http://dx.doi.org/10.1038/sj.onc.1210535 
Scientific Research Publishing (SCIRP) is one of the largest Open Access journal publishers. It is currently publishing more than 200 open access, online, peer-reviewed journals covering a wide range of academic disciplines. SCIRP serves the worldwide academic communities and contributes to the progress and application of science with its publication.

Other selected journals from SCIRP are listed as below. Submit your manuscript to us via either submit@scirp.org or Online Submission Portal.
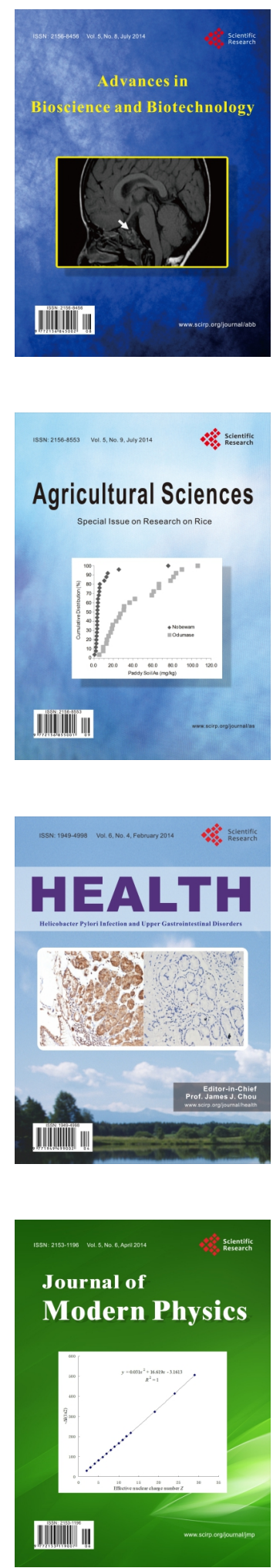
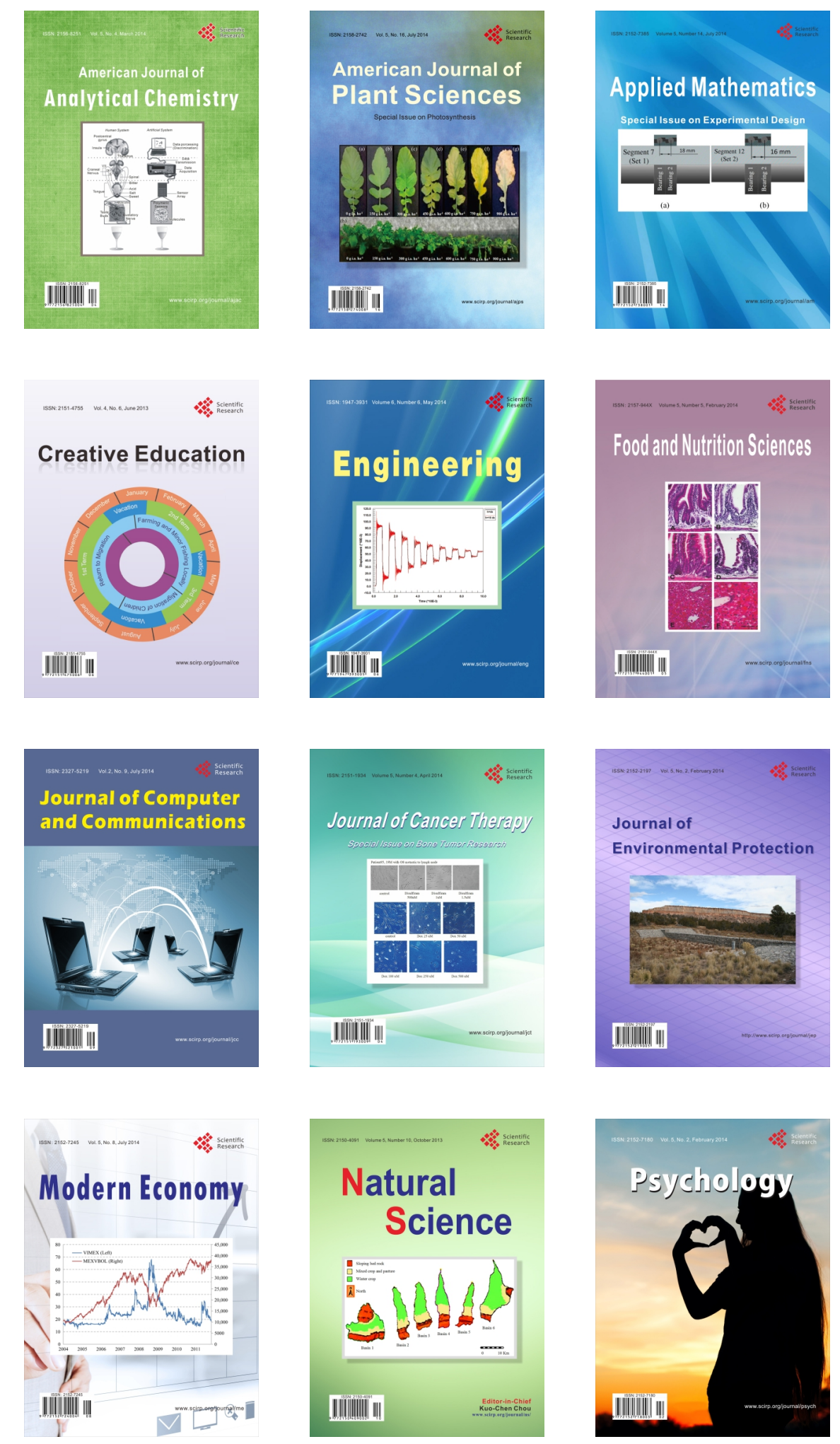